\title{
Exploring positive women's lives in Namakkal District, India
}

P. Kousalya

Deepika Ganju

Population Council

Follow this and additional works at: https://knowledgecommons.popcouncil.org/departments_sbsr-rh

Part of the Demography, Population, and Ecology Commons, Family, Life Course, and Society Commons, International Public Health Commons, and the Women's Health Commons How does access to this work benefit you? Let us know!

\section{Recommended Citation}

Kousalya, P. and Deepika Ganju. 2008. "Exploring positive women's lives in Namakkal District, India," Health and Population Innovation Fellowship Programme Working Paper no. 7. New Delhi: Population Council. 

This report is the result of a project entitled "Advocating for the Issues of Women Living with HIV/AIDS in India," undertaken as part of the Health and Population Innovation Fellowship (HPIF) awarded to the author in 2004.

The HPIF programme is administered by the Population Council, New Delhi and is a continuation of the MacArthur Foundation's Fund for Leadership Development (FLD) fellowship programme that continued over the period 1995 to 2004. The Council is grateful to the MacArthur Foundation for its support to this programme.

The HPIF programme aims to support mid-career individuals who have innovative ideas, leadership potential, and the capacity to help shape policy and public debate in the field of population, reproductive health and rights in general, with a focus on two priority themes - maternal mortality and morbidity, and the sexual and reproductive health and rights of young people. Since the transfer of the programme to the Population Council through 2006, a total of 17 individuals have been supported under the HPIF programme.

\section{For additional copies of this report, please contact:}

P. Kousalya

A-3, C Block, 4th Floor

Parsn Paradise Apartments

109, GN Chetty Road

T. Nagar, Chennai 600017

Phone: 044-28342801/ 04

email: poswonet@hotmail.com

Web site: www.pwnplus.org www.sociallight.in
Population Council

Zone 5A, Ground Floor

India Habitat Centre

Lodi Road, New Delhi 110003

Phone: 011-24642901/02

email: info-india@popcouncil.org

Web site: http://www.popcouncil.org/asia/india.html

The Population Council is an international, non-profit, non-governmental organisation that seeks to improve the well-being and reproductive health of current and future generations around the world and to help achieve a humane, equitable and sustainable balance between people and resources. The Council conducts biomedical, social science and public health research, and helps build research capacities in developing countries.

Copyright $\odot 2008$ P. Kousalya

About the authors: P. Kousalya is President, Positive Women's Network, a self-help organisation of women living with HIV in India; Joint Secretary of the Indian Network for People Living with HIV/AIDS (INP+); member of the Global Coalition on Women and AIDS, UNAIDS; and trustee member of the international community for women living with HIV/AIDS, representing the Asia-Pacific region. She has been working extensively for the rights of women living with HIV in India.

Deepika Ganju is an independent communications consultant. Her work has focused on the areas of social development and health, in particular issues concerning youth, reproductive and sexual health, poverty alleviation, and water and sanitation. She has documented and conducted research on these issues, and has also been associated, as a writer and technical editor, with the publication of books, journals, policy briefs, programme advisory notes, newsletters and field notes in these areas.

Suggested citation: P. Kousalya with D. Ganju. 2008. "Exploring Positive Women's Lives in Namakkal District, India," Health and Population Innovation Fellowship Programme Working Paper, No. 7. New Delhi: Population Council. 


\section{Exploring Positive Women's Lives in Namakkal District, India}

P. Kousalya

Fellow

Health and Population Innovation Fellowship Programme

with

Deepika Ganju

Communications Consultant 

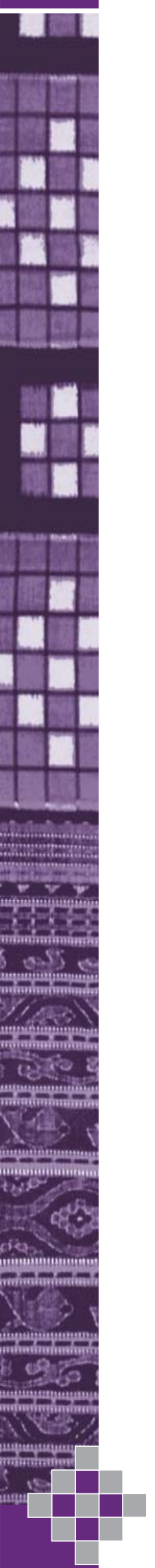


\section{Contents}

Introduction

Study setting

Methodology

Profile of study participants 5

Circumstances in which women found out about their HIV status

After husbands tested HIV-positive

In the course of seeking reproductive health services or curative treatment for themselves

Following children's ill-health 9

In the course of donating blood 10

Reactions to disclosure

Spousal relationship prior to and following disclosure of women's/partners' HIV status

Prior to disclosure

Following disclosure 14

Communicating HIV-positive status to spouse 14

Bitterness, blame and denial

Interaction with the family, friends and neighbours following disclosure of HIV status

Natal family

Marital family 18

Friends and neighbours 19

Interaction with health care providers following disclosure of HIV status 22

Counselling before or/and after testing for HIV 22

Type of health care providers/services accessed after disclosure 23

Indigenous or ayurvedic medicine 23

Allopathic medicine from qualified providers 24

Discrimination in hospital settings 24 
Women's suggestions for addressing HIV-positive women's needs 26

Livelihoods training and job opportunities 26

Food and nutrition 26

Children's education 27

Other forms of support 27

Summary of findings and moving ahead 28

Summary 28

Moving ahead 30

Acknowledgements 31

References 32

\section{List of Tables}

Table 1: Profile of study participants 5 


\section{Introduction}

In India, married women are generally not considered to be a group at risk of contracting or transmitting HIV; indeed, marriage is regarded as a protective factor against HIV infection as, for most women in India, sexual initiation occurs within marriage, and sexual relationships are by and large considered to be monogamous within marriage. As a result, programmes for the prevention of HIV have traditionally focused on high-risk women such as sex workers, and little attention has been given to married women. However, a growing body of evidence suggests that married women are at risk of acquiring HIV (Gangakhedkar et al., 1997; Kumar et al., 2006; Mehta et al., 2006; Newmann et al., 2000). For example, the recent National Family Health Survey reports an HIV prevalence rate of 0.19 percent among currently married women; 1.14 percent among women who are divorced, separated or deserted; and 1.51 percent among women who are widowed; a comparison of these rates with the prevalence rate of 0.03 percent among never married women suggests a close association between marriage and HIV prevalence among women in India (IIPS and Macro International, 2007).

While women in general face several disadvantages, including with regard to making informed sexual and reproductive health decisions, protecting themselves from infection, accessing services and exercising agency in their lives more generally, within the gender-stratified setting prevailing in India, HIV-infected women tend to be even further disadvantaged. Documentation of experiences of HIV-infected women, though limited, underscore that they face major financial constraints, child care and support problems, compromised health care seeking, marital problems, and emotional and mental health problems (Joseph and Bhatti, 2004; Majumdar, 2004; Thomas et al., 2005). Indeed, these issues compromise the lives of HIV-infected women far more adversely than their male counterparts.

Recognising the growing evidence on married women's risk of acquiring HIV and the increasing feminisation of the HIV epidemic in India, the National AIDS Control Programme III has called for strong prevention programmes targeted at women in the general population and programmes to improve psycho-social support to HIV-positive individuals, particularly marginalised women and children, by strengthening family and community care and addressing stigma and discrimination associated with the epidemic (NACO, 2007). The need for a more participatory and inclusive approach, which involves people living with HIV (PLWA) in framing polices and programmes (i.e., the greater involvement of PLWA), is also recognised.

In this context an initiative was undertaken to document the experiences of HIV-positive ever-married women in Namakkal district, Tamil Nadu. The initiative sought to explore the circumstances in which women learned about their HIV status; their feelings on finding out they were HIV-positive; the nature of husband-wife relationships prior to and following disclosure of women's HIV status; the extent of support or discrimination that women experienced from family members, friends and neighbours; treatment-seeking behaviours; and women's perspectives about ways in which the 
multiple needs of HIV-infected women can be met. Drawing on the testimonies of HIV-positive ever-married women gathered by trained investigators who were themselves HIV-positive, this report attempts to bring faces and voices to the reality of the HIV epidemic, particularly among married women. 


\section{Study setting}

This study was located in Namakkal district of Tamil Nadu, the state in which the first case of HIV was detected in India in 1986. Tamil Nadu was, till recently, one of the high prevalence states in India. However, recent evidence from antenatal surveillance estimates suggests that HIV prevalence in the state has declined in recent years, from 0.82 in 2003 to 0.58 in 2006 (NIHFW and NACO, 2007). Further, the recent National Family Health Survey reports that the HIV prevalence rate in Tamil Nadu was only slightly higher than the national average $(0.34 \%$ versus $0.28 \%)$. However, it is notable that the prevalence rate for women was comparatively higher than for men in the state $(0.39 \%$ versus 0.27\%) (IIPS and Macro International, 2007).

Namakkal district has a population of 1.5 million and a literacy rate of 67 percent (RGI, 2001). The district is well connected by state and national highways that link it with Chennai and other parts of the country. Although Namakkal is a high HIV prevalence district, it has few health facilities that address the needs of HIV-positive persons. While seven of the eight government hospitals located in Namakkal district provide general health/clinical services to PLWA, only one hospital provides HIV testing facilities and anti-retroviral treatment (ART) services.

Namakkal district was selected for the study for two reasons. First, the district has recorded the highest prevalence rate for HIV in the state of Tamil Nadu; 5.8 percent of women attending antenatal clinics in Namakkal district tested HIV-positive in 2003 and 3 percent tested positive in 2005 (TNSACS, 2005). Second, the Positive Women's Network $(\mathrm{PWN})$ has an active presence in the district. The PWN operates within the Indian Network for People Living with HIV/AIDS (INP+) to meet the needs of HIV-positive persons holistically by providing care, support and treatment services. In Namakkal district, the INP+ and the PWN, working through the district-level network, HIV Ullor Nala Sangam (HUNS), have recruited 1,200 network members and established care and support centres for PLWA (known as Positive Living Centres [PLC]), located in the towns of Namakkal, Paramathi Velur, Rasipuram and Tiruchengode. The staff of the centres periodically visit network members in their homes as part of a home-based care and support programme. 


\section{Methodology}

Study participants were recruited from among members of HUNS, the district-level network of people living with HIV. All the members of the HUNS network were listed (all members were ever-married), and 38 women selected to participate in the study. Study participants were selected so as to represent the variations in the socio-demographic characteristics of the network members.

In-depth interviews were conducted with all the members who gave their consent to be interviewed. Every effort was made to protect the confidentiality of the respondents. None of the interviews identified the respondents by name. In addition, to ensure that positive women were not identified or stigmatised, discussions were held with other women residing in the village about their health. In order to build rapport with the study participants, all the interviews were conducted by positive women who were trained to conduct interviews. The interviews were conducted in Tamil, transcribed and then translated into English.

During the interview, women were first asked general questions about themselves, such as their age, caste, family size and education status. After building rapport, women were asked more specifically about their experiences of being HIV-positive, including how they found out about their status; whether their family members were aware that they were positive; whether their relationship with their husbands had changed after being told of their HIV status; and whether they had faced stigma or discrimination from family members or in health care settings following disclosure. Women were also asked about whether they perceived their natal and marital family and friends to be a source of support. Discussions also covered positive women's access to care and support services.

The transcripts were analysed to capture typical patterns and exceptions with respect to selected themes, including the circumstances in which women learned about their HIV status, their feelings on finding out their HIV status, the nature of husband-wife relationships prior to and following disclosure of women's HIV status, experiences of support or discrimination from natal and marital family members, friends and neighbours, interaction with health care providers, association with networks of HIV-positive women and suggestions for addressing problems faced by HIV-positive women.

To bring voices to the reality of HIV-positive women's lives, two case studies of women's experiences of living with HIV and excerpts of their testimonies are presented in the report. 


\section{Profile of study participants}

Table 1 summarises the profile of study participants. Participants' age ranged between 20 and 40 years, with more than half aged below 30 years. Their educational profile indicates that 10 out of 38 participants had never attended school. However, half the participants had completed at least six years of schooling. The large majority (31/38) had children, some of whom were also HIV-positive. Their marriage profile shows that more than half (23/38) were widowed, 13 were currently married including three participants who had remarried following their first husband's death, and two were separated.

\section{Table 1:}

Profile of study participants

\begin{tabular}{|c|c|}
\hline Characteristic & Total $(\mathrm{N}=\mathbf{3 8})$ \\
\hline \multicolumn{2}{|l|}{ Age (years) } \\
\hline $20-29$ & 22 \\
\hline $30-40$ & 16 \\
\hline \multicolumn{2}{|l|}{ Years of schooling completed } \\
\hline None & 10 \\
\hline $1-5$ & 9 \\
\hline $6-9$ & 11 \\
\hline $10+$ & 8 \\
\hline \multicolumn{2}{|l|}{ No. of surviving children } \\
\hline 0 & 7 \\
\hline 1 & 10 \\
\hline 2 & 14 \\
\hline $3+$ & 7 \\
\hline \multicolumn{2}{|l|}{ Marital status } \\
\hline Widowed & 23 \\
\hline Currently married & 13 \\
\hline Separated & 2 \\
\hline \multicolumn{2}{|l|}{ Source of HIV infection } \\
\hline Women who indicated husbands as the source of infection & 35 \\
\hline Others* & 3 \\
\hline
\end{tabular}

Note: *Includes one woman who reported that she had acquired the infection as a result of being raped by an HIV-positive man, one woman who had a relationship with someone other than her husband who was HIV-positive, and one woman who had assisted in the delivery of an HIV-infected woman. 
Table 1 also presents information on the reported source of HIV infection. In the majority of cases (35/38), women reported that they had contracted HIV from their husbands.

I think my husband knew that he had HIV when he married me, and knowing he had the disease married me. (27 years, widow, 1 child, schooling up to Class 5)

When my brother-in-law came to know about my husband's HIV status, he took me to the general hospital [for an HIV test].... The result was positive. (30 years, widow, 2 children, schooling up to Class 5)

The remaining three women noted that they had got the infection from a source other than their husbands. One woman, for example, reported a relationship with someone other than her husband who was HIV-infected. Another said she had been raped by a man who had HIV.

I got HIV after I was separated from my husband.... I went to work in the fields and a man had forced sex with me. After some days this man died, and people said that he had HIV. (35 years, separated, 1 child, no schooling)

One woman, who worked as a nurse, reported that she had got the infection as a result of conducting the delivery of an HIV-infected woman.

I started thinking about how I could have got the infection. Then I knew.... I conducted a delivery for a woman without wearing gloves. They [hospital staff] didn't say anything then. Three days after I conducted the delivery, the attendant told me that the woman was HIV-positive. I asked her why she had not told me earlier. I said, "If you had told me, I would have been more careful, but now...." (40 years, married, 2 children, schooling up to Class 10)

Many women reported or suggested that their husbands had premarital or extra-marital relationships, and linked their husbands' sexual relationships outside marriage to their current positive status.

He told me that he had an affair with a girl in Chennai. (30 years, widow, 3 children, no schooling)

My neighbour said that he [my husband] had an affair with a woman. (27 years, widow, 2 children, schooling up to Class 7)

I asked my husband, "How does one get HIV?" He said, "If you have sexual relations with another girl, you will get it." Then I asked him, "Did you have a relationship with anybody?" He said, "Yes, before marriage, but not now." I shouted at him, "You have cheated me and tricked me," and began to cry. (27 years, widow, 2 children, schooling up to Class 5)

He [my husband] would roam around the bus stand and "talk" [have relationships] with many women. I told him not to go with these women.... My mother-in-law and father-in-law supported my husband; they said that as he is young, he will be like that. (27 years, married, 2 children, no schooling) 


\section{Circumstances in which women found out about their HIV status}

Women described varied circumstances during which they had found out they were HIV-positive. These situations typically included testing required following their husbands being diagnosed with HIV and disclosure in the course of interactions with a health care provider when participants sought reproductive health services or curative treatment for a general illness for themselves. A few also reported being told of their positive status after their children fell ill or prior to donating blood.

\section{After husbands tested HIV-positive}

Half the study participants found out they were HIV-positive when they had an HIV test after their husbands were diagnosed with HIV, when the couple underwent an HIV test in the course of seeking medical assistance for health problems experienced by their husbands, or when they took the HIV test following the death of their husbands. Typically, men themselves only found out that they were HIV-positive in the course of seeking medical assistance for health problems, including fever, blisters and sores, diarrhoea and vomiting.

In nine cases, women had an HIV test after their husbands tested HIV-positive. Of note is the finding that not all women were tested immediately after their husbands were diagnosed with HIV. Nor was testing done as a matter of course after their husbands were diagnosed as HIV-positive. Indeed, one woman recounted how the family had to argue with the hospital authorities to have her blood tested for HIV.

My husband would frequently complain of fever and a pain in his stomach, so we took him to hospital.... Later, because he became very sick, we took him to a private hospital; they asked him to have a blood test. They did not tell us the result but referred us to the general hospital. I could not believe that the result was HIV-positive. Then they asked me to take the test. The doctor informed me that the result was positive. (29 years, widow, 2 children, no schooling)

There too [at the general hospital] they did not test me. Only after my sister-in-law fought with them did they test me. (30 years, widow, 2 children, schooling up to Class 5)

However, in four cases, women noted that they had been asked to have an HIV test along with their husbands in the course of seeking treatment for health problems experienced by their husbands.

....my husband developed blisters on his mouth and lips after shaving. There were boils in his ears too. I took him to a private hospital. There they asked us [my husband, daughter and me] to have an HIV test. My husband and I both tested $H I V$-positive. (24 years, widow, 1 child, schooling up to Class 10) 
....he [my husband] suddenly fell ill with diarrhoea and became weak. We took him to a doctor... He asked both of us to have a blood test. The result showed that we had $H I V$. (26 years, widow, no children, schooling up to Class 6)

Some women (6/38) reported that were tested only after their husbands died.

Four months after my husband died, I went to hospital for a blood test. They told me that I was also HIV-positive. (30 years, widow, 2 children, schooling up to Class 6)

\section{In the course of seeking reproductive health services or curative treatment for themselves}

Of the 38 women, 17 reported that they had come to know about their HIV status in the course of seeking reproductive health services, mainly maternal health services, or treatment for general illnesses such as fever for themselves. Specifically, eight women reported that they had undergone an HIV test as part of a routine antenatal check-up or in the course of seeking treatment for complications experienced during pregnancy, including symptoms of reproductive tract infection, fits and inadequate growth of the foetus, or prior to delivery.

I became pregnant two months after marriage... We went for a check-up to a private hospital. They tested my blood and said that they could not do the check-up; they suggested we go to Chennai. We went to Erode and got tested. There they told my husband that both of us had HIV. (28 years, married, 2 children, schooling up to Class 5)

In the seventh month of pregnancy I had white discharge and itching in the genital area. We went to a private doctor and, on his suggestion, went for an HIV test. The result was positive. (27 years, widow, no children, schooling up to Class 5)

I became aware of my HIV status when I was in the eighth month of pregnancy.... The doctor said the child was not growing, so they asked me to have a scan. Then they asked me to have an HIV test. (28 years, widow, 2 children, schooling up to Class 8)

[I] used to have repeated spontaneous abortions.... Once, when I was pregnant, I had a seizure. I was asked to have an HIV test. Only then did we find out [about my HIV status]. (25 years, remarried, 1 child, schooling up to Class 10)

Another four women reported that they found out about their HIV status when they sought treatment for gynaecological problems, including delay in conceiving, heavy vaginal bleeding and symptoms of reproductive tract infection.

We found out [we were HIV-positive] when we went to test our inability to conceive. First we tested in Vellore and then in Coimbatore. (29 years, married, no children, schooling up to Class 1) 
I started getting white discharge and itching in the vagina. At that time, staff from the Positive Living Centre used to visit the village. I asked them to give me some medicine. They asked me to go to the general hospital for a blood test.... Then the staff from the Centre told me that I had tested HIV-positive and that I should get my husband tested as well. (37 years, widow, 1 child, no schooling)

One participant reported finding out about her HIV status in the course of seeking family planning services, i.e., female sterilisation.

After my daughter was born, my family said that I should have a family planning operation. We went to a private hospital. They asked me to give my blood for testing and took me to the operation theatre.... When the results came, the doctor said that the operation couldn't be done as my blood count was low. The doctor took me aside and told me that I should bring my husband, as he wanted to talk to him.... Then he told us that I had HIV. (27 years, widow, 2 children, schooling up to Class 5)

A few women (4/38) reported that they had found out about their status when they had sought treatment for what were perceived as minor health problems such as a bee bite or influenza.

A bee bit me.... A blood test was done.... then she [the doctor] told me that I had HIV. (40 years, married, 2 children, schooling up to Class 10)

I kept having fever continuously so I went for a blood test; only then did I learn about my status. (37 years, widow, 6 children, no schooling)

I had a cold and fever... both my husband and I had this problem so we went to the general hospital and got tested. They told us that both of us were HIV-positive.

(23 years, married, no children, no schooling)

Three years after my husband's death, I had fever and headaches repeatedly. I went to a private doctor. He asked me to have a blood test and I found out that I had HIV. (27 years, widow, 2 children, schooling up to Class 7)

\section{Following children's ill-health}

One participant reported that she was tested for HIV along with her child as her child was not keeping well:

My son's stomach was swollen, so he was tested for it [HIV]. He tested positive and then so did I. Then I came to know that my first husband also had HIV. (31 years, remarried, 2 children, schooling up to Class 8) 


\title{
In the course of donating blood
}

One respondent was diagnosed as HIV-positive when she volunteered to donate blood for a relative's operation:

\begin{abstract}
My sister's daughter was not well. I volunteered to donate blood as a relative's blood was required. The doctor tested my blood and I was told that I had HIV. They told me to get my husband tested. Then it became known that both of us had HIV. (39 years, widow, 2 children, schooling up to Class 5)
\end{abstract}




\section{Reactions to disclosure}

The narratives show that women typically expressed a range of feelings on being informed of their status, including despair, depression, suicidal thoughts, fear of death, feelings of being cheated and apprehensions about being ostracised for being HIV-positive. Not surprisingly, the most common reaction was one of despair and depression; 25 of the 38 women said that they had felt sad, upset and depressed. Moreover, the narratives suggest that some women felt depressed more on account of being left alone following the death of their husbands or finding out that their children were also HIV infected than finding out about their own HIV status. Some women (8/38) had even contemplated committing suicide.

When we [my husband and I] were told we had HIV, we were upset. I could not bear it. (31 years, widow, 1 child, schooling up to Class 6)

Except for my second son, all of us tested HIV-positive. We [my husband and I] could not accept the situation. We came home and cried inconsolably. I did not say anything to him [my husband]. My husband said we should all commit suicide. (28 years, married, 2 children, schooling up to Class 5)

....three of us [my husband, son and I] were tested.... all of us were HIV-positive. I could not bear it; I thought of committing suicide but I did not have the courage. (26 years, widow, 1 child, schooling up to Class 10)

....if it had been only me [who was HIV-positive], then it would not have mattered. But my son was also affected and I could not bear it. (38 years, widow, 4 children, schooling up to Class 12)

A few women (4/38) expressed apprehensions about experiencing discrimination from family members and the community.

If it becomes known [that I am HIV-positive], it will be shameful. How will I face other people? Nobody will touch me. How will I walk on the road? (26 years, widow, 2 children, schooling up to Class 10)

A few others (4/38) felt that they had been cheated by their husbands but, at the same time, had reconciled themselves to their situation and accepted their positive status as their fate.

When I came out of the hospital, I said to my husband, "I trusted and married you. Why you have done this to me? Why should I live now?" I shouted, "You have cheated me and tricked me." (27 years, widow, 2 children, schooling up to Class 5) 
I cried and asked him [my husband] why he had given me the disease after going to a place where no one should go. I said, "How happy we were.... why did you spoil our life?" (37 years, widow, 1 child, no schooling)

If only he had been true to me and told me about it [that he was HIV-positive],

I would have been happy that he had told me the truth. Till his death he did not say anything to me. I felt very bad but consoled myself thinking this is my fate.

(27 years, widow, no children, schooling up to Class 5)

As the following quote shows, a few women expressed their anxiety about how they would cope with their increased responsibilities.

At that time I thought, "Should I care for him [my husband] or myself? What will he do now? How am I going to manage the family? How am I going to take care of the children?" (26 years, widow, 2 children, schooling up to Class 10)

Finally, a couple of women said that as they did not know about HIV when they were informed about their positive status, they had not felt anything specific.

There was no specific feeling.... I didn't know anything [about HIV]. They [health care providers] told us that we [my husband and I] have HIV but they didn't say anything else. We didn't feel any fear. (29 years, married, no children, schooling up to Class 1) 


\section{Spousal relationship prior to and following disclosure of women's/partners' HIV status}

This section describes women's relationship with their husbands prior to and following disclosure of their or their partners' HIV status. We would like to caution readers that, as noted in an earlier section, several women came to know of their HIV status only after the death of their husbands or after their husbands had been diagnosed as HIV-positive; hence, some transcripts do not have information on the nature of the spousal relationship subsequent to the disclosure of women's HIV status. However, several transcripts provide insights on changes in the spousal relationship following women or their husbands being diagnosed as HIV-positive.

\section{Prior to disclosure}

Most women reported being in a happy and contented relationship at the start of their married life and prior to either partner being diagnosed as HIV-positive. Indeed, of the 38 study participants, 22 women reported that they had been happy, and their husbands had been affectionate and had taken good care of them when they had started living together.

I was young at that time [when I got married].... I was happy in my mother-in-law's house. My mother-in-law was very affectionate. I got pregnant two months after marriage. There was lot of happiness. (28 years, married, 2 children, schooling up to Class 5)

He [my husband] was happy with me. He never scolded me or beat me.

(23 years, married, no children, no schooling)

I had not been so happy even in my own house. My husband made me happy. (27 years, widow, 2 children, schooling up to Class 5)

Nonetheless, a few women (6/38) reported that their relationship with their husbands had not been a positive experience even at the beginning of their married life.

It was an arranged marriage. I was not taken anywhere, not even to see a film. He [my husband] would drink continuously and beat me. It was very difficult; and with my husband's daily wages being spent on drink, sometimes we did not have food.

(30 years, widow, 2 children, schooling up to Class 6)

Sometimes, they [my in-laws] treated me well; sometimes I would feel sad. (29 years, married, no children, schooling up to Class 1) 


\section{Following disclosure}

\section{Communicating HIV-positive status to spouse}

While in many transcripts women did not directly provide information on whether or not they or their husbands had informed their partners of the results of the HIV test, by and large, the narratives suggest that sharing of information on HIV status with partners was limited. Indeed, in six out of 38 narratives, participants clearly indicated that their husbands had not revealed their HIV status to them. Even when husbands were under medication, they did not tell their wives they were HIV-positive. In a few cases, women reported that they had been deliberately misinformed by their husbands about their health status.

From the time we got married he would take bags of medicines. When I asked him about it, he said that a bug had bitten him so he needed to take medicines.

(23 years, widow, no children, schooling up to Class 6)

Only then [when I went to the general hospital] was I told that my husband had HIV. Till then my husband lied to me saying that he had tuberculosis. (30 years, widow, 3 children, schooling up to Class 5)

His family knew that he had HIV but they did not tell me. He [my husband] asked his father to go to Kerala and buy medicine for this [HIV].... both of us took the medicine. I asked him why [I needed the medicine].... he said that the baby was not growing in the womb. I believed him.... After the delivery they [my in-laws] did not allow me to breastfeed my son.... When I asked why, they said that I had too much salt in my body. (23 years, remarried, 1 child, currently pregnant, schooling up to Class 6)

As the following excerpt suggests, women who were told of their HIV status in the course of seeking curative services for themselves were also reluctant to share their HIV status with their husbands or discuss related issues, including the need for their husbands to go for an HIV test or to have protected sex.

How can I ask him to go for an HIV test? I want to hide it [my HIV-positive status] from him. I don't want to tell him.... how will he get to know?.. I can't tell him to use a condom. He will ask me questions.... [When I found out about my status] I told him that the doctor said we should not have sex because I had a blood infection. We did not have sex for some time. Then he said that we should have sex, and that if I died, he would also die. (40 years, married, 2 children, schooling up to Class 10)

In an additional 14 cases, it appears that there was no spousal communication on either partners' HIV status or how they had acquired HIV. In most of these cases, the narratives suggest that women came to know about their partners' HIV status from a health care provider or family member. 
At the government hospital, they found out that my husband was HIV-positive; they told his brother his status.... A week later he [my husband] was unable to eat anything. I took him to a doctor. The doctor told me that my husband was HIV-positive and advised me to stay away from him. (30 years, widow, 2 children, schooling up to Class 6)

My husband would suffer from fever and cough frequently. A person from the Centre [PLC] said that he should be taken to the general hospital for an HIV test.... A week later, a woman came from the Centre and said that both of us had HIV. (30 years, widow, 3 children, no schooling)

Indeed, in only 12 cases did women and their husbands share information about their HIV status with their spouses, either directly or indirectly.

Nobody told me, but my husband told me to get a blood test done. (23 years, widow, no children, schooling up to Class 6)

....the doctor tested my blood and then I knew I had HIV. They told me to get my husband tested. At that time, he [my husband] was out of the village driving a truck. We told him to come back immediately and he was tested. (39 years, widow, 2 children, schooling up to Class 5)

\section{Bitterness, blame and denial}

In many instances, women reported that their relationship had become acrimonious subsequent to either partner testing positive for HIV. In eight cases, participants said that their husbands had started shouting at them and had picked a fight for no reason.

.... when he [my husband] was told he had HIV, he started fighting with me.

(23 years, remarried, 1 child, schooling up to Class 6)

He [my husband] told me not to tell anybody [about his status] and tortured me a lot. (35 years, married, 3 children, schooling up to Class 6)

He [my husband] was always irritated with me. (30 years, widow, 3 children, schooling up to Class 5)

Moreover, in two cases, husbands had blamed their wives for transmitting the infection. However, we note that in one of these cases, the participant had remarried following her first husband's death and in the other, the participant had engaged in a premarital relationship.

My husband said, "You said that your [first] husband died as a result of HIV... I do not know whether I got HIV from you or you got it from me." (25 years, remarried, 1 child, schooling up to Class 10) 
Right from the time we got married I had problems [I loved a man but did not marry him, and my husband came to know of this later]. HIV made it worse. He [my husband] started blaming me for the infection.... he would be irritated by just the sight of me. (29 years, married, 2 children, schooling up to Class 3)

In another four cases, women said that their husbands had refused to believe the test results when they were told of their partners' or their own HIV status; indeed, some had refused to go for an HIV test, seek treatment or comply with treatment.

[When] I came to know about my status... I asked my husband to get tested for HIV, but he refused. (37 years, married, 6 children, no schooling)

He [my husband] said that they [the doctors] were lying [that he has HIV]. (27 years, married, 2 children, no schooling)

After that [finding out he was HIV-positive], my husband did not go to hospital for five months; he stayed at home, just lying down. (31 years, widow, 1 child, schooling up to Class 6)

....he [the doctor] prescribed medicines.... My husband refused to take them saying that he did not have any problems. Only I took the medicines. (27 years, widow, no children, schooling up to Class 5)

Nonetheless, a few women (6/38) reported a supportive relationship even after one of the partners tested HIV-positive, including trying to find out more about the disease, seeking treatment together and comforting each other.

.....my husband started buying books and reading them to find out whether medicines are available and how to live with HIV. (28 years, widow, 1 child, schooling up to Class 7)

My parents said, "This is enough, my daughter need not live here anymore, we will take her away." I replied, "What has happened has happened. I will stay here with him [my husband]"... Then both of us bought and consumed indigenous medicines. (27 years, widow, no children, schooling up to Class 5) 


\section{Interaction with the family, friends and neighbours following disclosure of HIV status}

The study also explored the extent to which women received support or faced discrimination from family members following disclosure of their HIV status (see Box 1 and Box 2, which present contrasting experiences of women's experiences of support, described in their own words). The narratives clearly indicate that the extent of support or discrimination that HIV-positive women experienced differed between the natal and marital family.

\section{Natal family}

Most women (23/38) reported that members of the natal family had been supportive even after being told of their HIV status. Natal family members had provided emotional and financial support, and had accompanied women for treatment. Several women noted that they were in fact staying with members of the natal family. In the majority of cases, women reported that all members of the family were supportive.

My parents give me a lot of support. They are everything to me. (40 years, married, 2 children, schooling up to Class 10)

My mother, brother and grandmother are aware that I am HIV-positive. They are affectionate to me. My sister's daughter is with me and she is very caring. (23 years, widow, no children, schooling up to Class 6)

.... when I was diagnosed as HIV-positive, he [my father] became very affectionate and caring. (24 years, widow, 1 child, schooling up to Class 10 )

My relatives know [I have HIV]; they all console me.... My father and mother are supportive. (27 years, widow, no children, schooling up to Class 5)

While most women had received support from their natal family, a few women (4/38) said that they had not revealed their HIV status to their natal family members as they were apprehensive of experiencing discrimination or were concerned about family members worrying about them.

My sister and brother do not know [about my HIV status]. If they get to know, they will never look at me. My younger brother will kill me. (35 years, separated, 1 child, no schooling)

I hid it [HIV status] from my family. How can I tell them? They will feel very bad. I didn't tell anyone. I just kept it to myself. (40 years, married, 2 children, schooling up to Class 10) 
When my husband was diagnosed as HIV-positive, they [my relatives] hardly came to see us.... if they find out that my son and I are also HIV-positive, I do not know how they will react. (39 years, widow, 5 children, teacher's training certificate)

My parents and siblings live far away... I have not told them I have HIV because they will worry. (30 years, widow, 3 children, schooling up to Class 5)

Another two women reported that they had experienced discrimination from their natal family. ....since my son has HIV, my younger brother feels that his children will also get the disease.... they chase us away and they don't talk to us. (27 years, married, 2 children, no schooling)

Nobody [my relatives/my husband's relatives] comes home. My brother and sister also never come. They don't even speak to me when they pass by. (23 years, remarried, 1 child, currently pregnant, schooling up to Class 6)

\section{Marital family}

While most women had received some assistance from their natal family, only a few women (5/38) specifically stated that they had received support from members of their marital family. For example, women described how their in-laws had been a source of support and affection, and had visited the couple even after being told about their HIV status.

My in-laws... know about our status.... Everyone is very understanding and loving. My sister-in-law and brother-in-law are taking a lot of care of us. (23 years, married, no children, no schooling)

For us, our total support is my in-laws.... my husband's sister is also affectionate. Nobody has isolated us after knowing our HIV status. Everybody is more affectionate now than before. (28 years, married, 2 children, schooling up to Class 5)

Nobody has discriminated against us. My in-laws visit us often. (24 years, widow, 1 child, schooling up to Class 10)

The majority of women (17/38) reported that their marital family had discriminated against them, refused to give them their share of property and had not even offered emotional support. Testimonies also include cases in which women sought the assistance of the community to get their share of property.

After he [my husband] died and all the rituals were over, they [my in-laws] told me that both my husband and I had HIV. I was very upset. My relatives organised a panchayat [community] meeting. At the meeting, my mother-in-law said, "My son is dead. My daughter-in-law will also die in three months. Why should we give her any money?" My husband had a life insurance policy; they did not even give me that money. They said that the money was not enough to even settle the debt incurred for 
my husband's medical treatment. Then I went back to my mother's house. (23 years, widow, no children, schooling up to Class 6)

When I asked for half the property, my brothers-in-law refused to give it to me. Then all the people in the village intervened and I was given Rs. 70,000. (28 years, widow, 1 child, schooling up to Class 7)

They [my in-laws] knew about our status. They asked us whether this disease is curable. Other than that they did not say anything. (25 years, married, 3 children, no schooling)

My mother-in-law says that only I have HIV and not my husband. (27 years, married, 2 children, no schooling)

As with the natal family, some women (2/38) did not disclose their HIV status to members of their marital family fearing an adverse reaction from them.

We did not tell anyone.... They [my in-laws] asked why people from the Positive Living Centre are visiting me. I told them that they come because I don't have a child. So they don't mind. (29 years, married, no children, schooling up to Class 1)

\section{Friends and neighbours}

We note here that some 18 transcripts have no information on whether or not women had revealed their HIV status to their friends and neighbours, or how they had reacted to disclosure of their status. The narratives that include such information suggest varied responses from friends and neighbours.

In many cases ( 8 of the 20 women for whom information was available), women did not reveal their status to their friends and neighbours because they were apprehensive about the consequences of disclosure.

My neighbours do not know that I have HIV.... If my HIV status becomes known, I may be asked to stop coming to work. So I don't want to tell anybody. (30 years, widow, 3 children, no schooling)

Nobody here knows of this [my status].... if they get to know I don't know how they will react so I have not told anyone. (23 years, remarried, 1 child, currently pregnant, schooling up to Class 6)

Women were also reluctant to have their children tested for HIV, even when they had been advised to do so, as they were apprehensive about facing negative consequences. For example, one woman had not had her son tested as she felt "he should not be humiliated" (30 years, widow, 2 children, schooling up to Class 6).

Another four women reported that their neighbours had socially boycotted them after they had disclosed their status. Indeed, one couple reported that they had shifted from their native village because they had been ostracised by the community. 
Everybody in the village knows about this [my HIV status]. They don't talk to me.... if I offer them something to eat they will not take it... My son and I live in isolation and we suffer a lot. (35 years, separated, 1 child, no schooling)

When it became known that I had HIV, my neighbours and others treated me and spoke about me differently. They would say that people with HIV die very quickly. They would not take anything from our house. (27 years, widow, 2 children, schooling up to Class 5)

All of them [neighbours] came to know about our status, and they kept away from us. That is why we shifted our residence. (37 years, married, 6 children, no schooling)

....the neighbours look at me like I am an enemy. (31 years, widow, 1 child, schooling up to Class 6)

Nonetheless, eight women reported that their peers and neighbours were empathetic.

Friends come [to my house] if there is a function. They all know about my HIV status but nobody discriminates. They are more caring than before. I live with my parents but I think of my friends first. Certain things cannot be shared with parents. Also, if I am sad, they [parents] will also be upset but my friends will comfort me. (27 years, widow, 2 children, schooling up to Class 5)

My neighbours behave well with me. (24 years, widow, 1 child, schooling up to Class 10)

\section{Box 1: "I have no support"}

Sunita, * a 30 year-old widow, has three children. She has studied up to Class 5.

"When my brother-in-law came to know about my husband's HIV status, he took me to the general hospital. Only then was I told that my husband had HIV. Till then my husband lied to me saying that he had tuberculosis. I was very upset. For days I could not eat, and I kept crying about my fate.

"My mother-in-law had always been kind to me. However, when my in-laws were told that my husband had HIV, they started fighting with us. I was very upset.

"My husband was always irritated with me. When he died, I was very depressed but I consoled myself thinking about my children.

"My neighbours do not know that I have HIV. My parents and siblings live far away. I have not told them I have HIV because they will worry and they cannot support me financially.

"I took a loan to pay for my husband's treatment. Now all those who lent me money are saying bad things about me. My mother-in-law scolds me and speaks ill of me; I have no choice but to stay with her.

"I have no support except that my brother-in-law accompanies me to hospital."

* Respondent's name has been changed. 


\section{Box 2: "No one discriminates against me"}

Rani, * a 29 year-old widow, lives with her mother, father and brother. She has two children. Her son is HIV-positive. She has had no schooling.

"I was married at the age of 21 . My husband would frequently complain of fever and a pain in his stomach, so we took him to hospital. They asked him to have a blood test. I could not believe that the result was HIV-positive.

"Then they asked me to take the test. Only after proper counselling did the doctor tell me my status. It was very difficult for me to accept the situation. He told me that people with HIV live for a long time, so I should not be scared. Then I gained confidence and started taking treatment.

"After my husband died, my son tested HIV-positive. I was very upset. Every time I thought about it I wept till I joined the Centre (PLC).

"I first told my mother my status; then I told my in-laws. They have assured me of their support. My in-laws look after me well. They visit me and comfort me. My mother-in-law takes my children to her house. She gives us new clothes and money. She is affectionate and does not discriminate against us because we have HIV.

"A few friends/neighbours are aware of my HIV status. When my husband died, it became known that he had HIV. At that time, my neighbours also came to know about my status. However, they all treat me well. I have told my parents that when I die, they should take care of my children.

"I know there are self-help groups in the community. I have joined a self-help group managed by the Centre and I am thinking of starting a small business through this group.

"I feel comforted when I go to the Centre. At meetings and counselling sessions, we are told about HIV. We are also given a check-up by the doctor. The Centre takes us for CD4 testing. My son and I are on ART. Now we feel confident when we meet other people with HIV. The Centre also supports our children's education and provides them with nutritious food, uniforms and notebooks.

"No one discriminates against me."

* Respondent's name has been changed. 


\section{Interaction with health care providers following disclosure of HIV status}

This section discusses women's interaction with health care providers when they underwent HIV testing and subsequently sought treatment for complications experienced. Specifically, the section explores whether women were counselled before or/and after HIV testing, the type of providers from whom women sought health services after testing HIV-positive and whether women had experienced discrimination in heath care settings.

\section{Counselling before or/and after testing for HIV}

While policies emphasise the need for counselling HIV-positive persons before they undergo the test as well as when the test result is disclosed, few women reported that they or their spouses had been given information on living with HIV when they had tested HIV-positive. Of the 22 women who specifically discussed counselling in the interview, 17 noted that they had not been counselled either before or after undergoing the HIV test and being told of their status.

No [they did not provide any counselling]; they told us that there is no use spending money as he [my husband] will soon die. (35 years, widow, 1 child, schooling up to Class 3 )

At that time I did not know anything about HIV. I did not receive proper counselling. (27 years, widow, 2 children, schooling up to Class 5)

Only five women mentioned that the provider had discussed issues related to living with HIV, ART, and so on when disclosing the test result.

Only after proper counselling did the doctor tell me my status.... He told me that now medicines are available for this disease. He also said that with these medicines, if I have a nutritious diet, I can live a healthy life. He said that now people with HIV live for a long time, so I should not be scared. Then I gained confidence and started taking treatment. (29 years, widow, 2 children, no schooling)

Moreover, women were not always informed immediately after the test that they were HIV-positive. In one case, a woman was tested twice but was not told her status.

When I was six months pregnant, I had a blood test. The doctor told me I had a problem in my blood. They referred us to another city; we did a blood test again, but there too they did not tell us anything. (28 years, widow, 1 child, schooling up to Class 7 )

Given that several women were not given any counselling, it is not surprising that they reported misconceptions regarding HIV, including about methods of transmission and how to live with the disease. 
I did not know anything about HIV. I thought that he [husband] was possessed by evil spirits so I took him to the temple. (26 years, widow, no children, schooling up to Class 6)

I thought HIV makes a person thin. I didn't know I can live a healthy life like other people. (26 years, widow, 2 children, schooling up to Class 10)

I did not know what HIV was. I thought that if you got it, you would become "skin and bones" and die. (27 years, widow, 2 children, schooling up to Class 5)

At that time [when my husband was diagnosed with HIV], I did not know what HIV was or where it should be treated. (38 years, widow, 5 children, teacher's training certificate)

\section{Type of health care providers/services accessed after disclosure}

All the study participants and their husbands reportedly accessed some care after being told of their HIV status; however, the providers/services that they sought varied. The narratives suggest that women sought services from multiple providers, including qualified and unqualified providers, and those practising allopathic and Indian systems of medicine.

\section{Indigenous or ayurvedic medicine}

Some 10 women reported that they had taken indigenous or ayurvedic medicine; in the course of treatment-seeking, women resorted to using the services of an array of such providers, often at considerable cost. We note here that it is difficult to establish from the narratives how many of these providers were qualified or unqualified. However, in most cases, the services provided were reported to be ineffective.

We bought and consumed traditional medicines... [after that] my husband had fever and a bloated stomach, and could not eat. (27 years, widow, 2 children, schooling up to Class 5)

Both of us went for treatment to a doctor of traditional medicine nearby. He told us that when taking the medicine, only some food items should be consumed.... A week after starting the treatment, my husband could not walk. (24 years, widow, 1 child, schooling up to Class 10)

My husband and I took indigenous medicines available in Vellore. Then we went to Kerala because we were told that the medicine was available there. We got the medicine twice.... After taking the medicine, my husband began to lose weight... so we discontinued the medication. (39 years, widow, 2 children, schooling up to Class 5)

The doctor who tested us was an ayurveda doctor. He said that he would prepare medicine for this [HIV].... We spent nearly Rs. 60,000 on his [my husband's] treatment but there was no improvement... Then we went to Kerala for treatment.... My husband's condition did not improve.... I took him to Pondicherry... He was there for six days. (26 years, widow, no children, schooling up to Class 6) 
A friend said that siddha medicine is given for this [HIV]. So I mortgaged my land and bought the medicine for my husband. (38 years, widow, 5 children, teacher's training certificate)

\section{Allopathic medicine from qualified providers}

More than half the participants (24/38) had sought services, including CD4 testing and ART, from selected government hospitals. We note here that all the participants in this study were members of the PWN and the testimonies underscore that their association with the network played a critical role in encouraging several of these participants to seek appropriate services.

....my husband was referred to the general hospital for CD4 testing. He has been taking ART for about a year. My elder son and I had a CD4 test in the general hospital. Now both of us are also on ART and we have no problem. (28 years, married, 2 children, schooling up to Class 5)

I was taken to the government hospital for a CD4 test. Now I am taking ART and I feel better. (35 years, separated, 1 child, no schooling)

I got to know about HIV only after coming to the Positive Living Centre. I was given counselling here. The Centre's doctor gives me check-ups. They have also made arrangements for me to get ART. (23 years, widowed, no children, schooling up to Class 6)

\section{Discrimination in hospital settings}

Many study participants and their spouses had sought services from qualified providers after they received support from the PWN and the Positive Living Centre; these women typically did not experience discrimination. However, six women specifically mentioned that they had faced discrimination in health settings. Women reported, for example, that health staff had refused to provide services and that they had to seek care from personnel who were not aware of their status.

[When he found out we were HIV-positive] the doctor refused to provide treatment and asked us to go to another hospital. (24 years, widow, 1 child, schooling up to Class 10)

When they [health providers] saw the test result [that I was HIV-positive], they told us not to have the delivery there.... I went to another facility in the last stage. (28 years, widow, 1 child, schooling up to Class 7)

They took me to the operation theatre for the delivery. They asked me to have a blood test before my operation.... They abused me during the operation. They never came near me after I left the operation theatre. (29 years, married, 2 children, schooling up to Class 3 ) 


\section{Association with networks of positive people}

As noted in an earlier section, all the study participants were members of the PWN. The vast majority (35/38) specifically discussed how networks of positive persons had provided them emotional support, in addition to providing counselling services, health services and income generating opportunities.

After coming here $[P L C]$, we received counselling... If we have a medical problem, the doctor at the Centre treats us and gives us medicine. They [staff at the PLC] are helping to educate our children. They also buy provisions for us. Now I come to the Centre and sew handkerchiefs. They provide opportunities for employment based on our skills. Coming here is peaceful and comforting. (28 years, married, 2 children, schooling up to Class 5)

I thought I was the only person who was affected by HIV, but after meeting others at the Centre [PLC] who are also affected, I have been able to cope with my situation. (37 years, married, 6 children, no schooling)

I was very upset when I was told about my son's positive status. Every time I thought about it, I wept till I joined the Centre [PLC]. I feel consoled and comforted when I come here. (29 years, widow, 2 children, no schooling) 


\section{Women's suggestions for addressing HIV-positive women's needs}

During in-depth interviews, women identified their priority needs and suggested ways to address the problems that HIV-positive women experience in their day-to-day lives. These are discussed in this section.

\section{Livelihoods training and job opportunities}

In the course of interviews, several women noted that they were financially insecure as they had not been able to work following the onset of the disease. For many women, being HIV-positive had taken a toll on their lives. Their failing health had meant loss of work and consequently, loss of income. Being HIV-positive had also been a drain on their finances as, in many cases, couples had borrowed money to pay for treatment.

I cannot go to work like before... I need to give my son milk and eggs every day.... I cannot eat nutritious food as I have no income. (27 years, widow, 2 children, schooling up to Class 7)

When I am well I go to work; otherwise I stay at home... I work for three days and rest for the remaining part of the week. (35 years, widow, 1 child, schooling up to Class 3 )

I took a loan to pay for my husband's treatment. (30 years, widow, 3 children, schooling up to Class 5)

Hence, not surprisingly, half the study participants expressed the need to provide livelihoods training and to link women with opportunities for employment.

If something can be done so that I can generate some income, I would be happy. (37 years, widow, 1 child, no schooling)

If they give me a job it would be helpful. There are not enough earnings. We are staying separately [from the natal/marital family]. It would help if we are taught embroidery and tailoring. (31 years, married, 3 children, schooling up to Class 8 )

If training is given in a field where I can earn a good income, I would be happy.... I am confident that I can live if I have an income and do not have to depend on anyone. (26 years, widow, 1 child, schooling up to Class 10)

\section{Food and nutrition}

Closely related to their economic situation described above, and linked to the need for HIV-positive persons to have proper nutrition, some women (4) reported experiencing 
difficulty in getting adequate food and nutrition, and suggested that HIV-positive women should be given such support.

If they provide us rice and cereal, it would help us meet our food and nutrition requirements. I am looking for work opportunities. If the Centre [PLC] helps by providing me a job, I will be grateful. (25 years, married, 3 children, no schooling)

\section{Children's education}

Many women had to cope with the added responsibility of bringing up children who were HIV-positive. Women's HIV-positive status also raised the issue of the need to educate their children and make them financially independent, perhaps reflecting their concerns about their own failing health and leaving their children orphaned. Five women specifically mentioned the need for support to educate their children.

It would help if I got support for my children's education. (37 years, married, 6 children, no schooling)

It is enough if my children are educated. I do not want anything else. (38 years, widow, 5 children, teacher's training certificate)

It would be helpful if they [PLC] gave me a job and I got some money to support my child's education. (32 years, separated, 1 child, no schooling)

\section{Other forms of support}

A few women (2) expressed the need for support to build a house; another three mentioned the need for assistance in getting medication.

We don't have a proper house. It would be good if we could get assistance to build a house. (25 years, married, 3 children, no schooling)

Sometimes we are asked to buy the medicines ourselves. If this can be arranged it would be good. (27 years, widow, 1 child, schooling up to Class 5)

One woman articulated the need for adopting a holistic approach to address the problems of PLHA. She suggested that the platform of positive networks could be used to advocate for the needs of PLHA and to address their concerns:

They [positive networks] should advocate for HIV-positive people to start a life insurance policy; it would be useful for their children.... As we get only some medicines and have to buy the rest, it would be nice if such networks could provide medicines.... Many people like me do not have a house... positive networks should ask the Government to allocate houses to positive persons like me. We should have a care home with a doctor, medicines and other facilities. If someone is very sick he can go to the care home. Widows should get a pension. Training should be given to HIV-positive people and work opportunities created. I would like to start a company and give HIV-positive people work. (29 years, widow, 2 children, schooling up to Class 6) 


\section{Summary of findings and moving ahead}

\section{Summary}

This report documents the experiences of 38 ever-married women living with HIV who were members of the PWN, a network of positive persons. The study was located in Namakkal district, Tamil Nadu, an area with a high concentration of HIV-positive persons, a number of intervention projects for PLHA and an active positive women's network. The study drew on the testimonies of positive women to document the circumstances in which they were told of their positive status, relations with their husbands before and after disclosure of their or their partners' HIV status, and the sources of support following disclosure. Recognising the need to give PLHA themselves a voice in programme design, study participants were also asked to identify the priority needs of HIV-positive women and to suggest ways to address these needs.

Common themes and patterns emerged from women's narratives. The vast majority of women $(35 / 38)$ reported that their husbands had transmitted the infection to them, a finding that underscores married women's vulnerability to HIV. Narratives show that women's vulnerability was further compounded by their low perception of self-risk. Indeed, none of the women had opted to undergo a routine HIV test; in most cases, women had found out about their status only inadvertently, when they had been advised to take an HIV test after their husbands had been diagnosed with HIV, or in fewer cases, when they had sought care for general health or reproductive health problems for themselves.

Findings also indicate that women and their husbands were poorly informed about HIV; they had limited awareness of how HIV is transmitted, how to live with the disease and its links with risky sexual behaviours. Moreover, while policies stress the need for preand post-test counselling, women's testimonies reveal that in most cases, women and their husbands had not been given information on issues related to living with HIV, the availability of appropriate heath care services, ART, and so on when they were informed of their status by health providers.

Reactions to disclosure of their HIV status were, as expected, of sadness, despair and despondency. Most women, however, also reported that their initial feelings on finding out their status even extended to thoughts of suicide.

Findings show that women were not always informed of their husbands' positive status or asked to take an HIV test after their husbands were diagnosed with HIV. Indeed, some women reported that they had undergone the HIV test after their husband's death, resulting in delayed care seeking.

Although women, by and large, described the spousal relationship in the initial years of marriage as happy, narratives reveal that following disclosure of women's/husbands' HIV status, the spousal relationship appears to have undergone a change. Partners seldom discussed their HIV status with each other or how they had acquired the disease; 
indeed, while some husbands had withheld this information from their wives, others had deliberately misled their wives about their health status. Even the few women who indicated that they had contracted the infection prior to their husbands acquiring HIV were reluctant to share their status with their husbands. Indeed, of the women who specifically discussed whether or not they/their husbands had shared information about being HIV-positive, only 12 reported that they/their husbands had shared their status with their partners. Several women noted that their relationship with their husbands had become acrimonious following disclosure of their or their husbands' status.

While all women and their husbands had accessed some care following disclosure, they did not necessarily seek care from an appropriate facility. Various providers were consulted, including qualified and unqualified providers, and those practising allopathic and indigenous systems of medicine. While more than half the respondents had sought services for testing and treatment from a public facility, some women had taken indigenous/ayurvedic medicine and had used the services of multiple providers often at a considerable cost. While the tendency to seek treatment from unqualified providers/ traditional providers may have been out of a sense of desperation to seek quick treatment and access any kind of care that was available, it perhaps also reflects the fact that women were poorly informed and counselled regarding appropriate options for treatment and care.

Despite the despair, insecurity and isolation that many women experienced on being told of their status, some women reported receiving considerable support from natal family members following disclosure of their HIV status, including financial and emotional support as well as assistance in accessing treatment services. While women also reported receiving assistance from neighbours and friends, few women reportedly received any support from members of the marital family following disclosure. Indeed, more than half the women reported that the martial family had discrimination against them, refusing to give them a share of the property or even provide financial or emotional support. In a few cases, women experienced discrimination in hospital settings, which had compromised their treatment seeking. Fearing such consequences, some women preferred not to disclose their status, opting to live in a "culture of silence".

The vast majority of women stressed the positive role of formal support mechanisms, such as the PWN and the Positive Living Centre (of which they were all members), in helping them come to terms with their lives and addressing many of their critical needs, including medical treatment, livelihood opportunities and children's education.

Women themselves identified their priority needs and ways to address these needs in the future. Findings show that providing financial security for positive women and ensuring a secure future for their children were major concerns; specifically, study participants mentioned the need to impart livelihood training linked to job opportunities, ensure that HIV-positive women are provided food and nutrition supplements, ensure support for their children's education, and enable positive women to meet their medical expenses as key ways to move ahead. Women also recognised that the needs and concerns of HIV-positive women must be addressed holistically, using networks of positive persons to advocate their cause. 


\section{Moving ahead}

It is clear from the testimonies presented in this report that married women who are HIV-positive have specific needs and vulnerabilities, and efforts are required at various levels to address these needs. Given that most women and their husbands were poorly informed about HIV and related issues, there is an urgent need for programmes to build awareness among young women and their partners about HIV, as well as sexual and reproductive health matters more generally. Moreover, the finding that women in the study had a low perception of self-risk of acquiring and transmitting HIV suggests that interventions should also focus on raising awareness among women and their partners of the need to undergo HIV testing, and for married couples to adopt protective actions, such as using condoms in marital relations, to prevent the transmission of HIV.

Few women in the study had received counselling on HIV despite policies that emphasise the need to provide information and services to PLHA. Health workers should be sensitised to the need for providing pre- and post-test counselling on HIV-related issues to clients who are undergoing the test, and to address the concerns of HIV-positive persons sensitively. At the same time, steps should be taken to protect those who are diagnosed as HIV-positive from seeking the services of unqualified providers and to ensure that they are made aware of available and accessible health care services.

Counselling services need to go beyond providing only information to positive persons on HIV testing and treatment. Findings show that most women's initial reaction to learning of their HIV-positive status was an overwhelming sense of helplessness and even thoughts of suicide; in this context, interventions would need to focus on providing appropriate counselling services at the time of disclosure to address the emotional and mental health needs of HIV-positive persons including feelings of depression so commonly reported by women in the study. Further, the finding that many women experienced marital discord following disclosure underscores the urgent need to address the lack of communication between spouses; couples should be provided marital counselling, particularly following disclosure, so that both partners can live safe and healthy lives.

The narratives indicate that positive women faced stigma from family members in health care facilities as well as in other spheres of life. Efforts should be made to create an enabling environment so that HIV-positive women can lead their lives without being discriminated against in various settings, including at the community level and in health care facilities. Sensitisation programmes at the community and health sector levels are needed that will allay misconceptions about positive people, address issues relating to stigma and discrimination, and stress the supportive role families, communities and the health sector can play in the well-being of positive people. At the same time, networks of family, friends, neighbours and the wider community need to be developed and involved in the process of providing HIV-positive persons holistic support. More formal support mechanisms, such as networks of positive persons, have been described as providing a source of considerable support, and positive women should be enabled to access such networks. 
Most important are measures that will enable positive women to become self-reliant. Repeated themes articulated in the narratives were women's concerns about financial security and support for their children. Ways of ensuring financial security for positive women, notably the widowed, separated and abandoned, and meeting their need for multiple services should be explored.

This report, which draws on narratives of the lives of HIV-positive women as told by women themselves, shows that women living with HIV face multiple vulnerabilities, ranging from physical and mental ill-health to concerns about financial security, family and peer support and securing the future of their children. Findings call, correspondingly, for multiple efforts that address positive women's health and well-being as well as empower them to lead their lives with confidence and dignity.

\section{Acknowledgements}

Several people provided valuable assistance during the course of this project. I am grateful to the members of HUNS for selecting the study participants; members of the field team-Selvi, Gandhimathi, Krithika and Kavita—for interviewing the study participants and documenting their stories; and Punitha, Swaminathan and Inbaraj for transcribing and translating the interviews. A special thanks to Mary Julie and Jeyapaul for their help in overseeing the project.

I would also like to thank the women who were interviewed during this study, who generously gave their time to share their experiences.

I am grateful to Shireen Jejeebhoy, K.G. Santhya, Shveta Kalyanwala and Komal Saxena at the Population Council for their guidance throughout the study and on previous versions of this report. I would also like to thank Radhika Ramasubban for reviewing the report. 


\section{References}

Gangakhedkar, R.R., M.E. Bentley, A.D. Divekar et al. 1997. "Rapid spread of HIV infection among married monogamous women attending STD clinics in India," Journal of American Medical Association 278: 2090-2092.

International Institute for Population Sciences (IIPS) and Macro International. 2007. National Family Health Survey (NFHS-3), 2005-06: India, Volume 1. Mumbai: IIPS.

Joseph, E.B. and R.S. Bhatti. 2004. "Psychosocial problems and coping patterns of HIV seropositive wives of men with HIV/AIDS," Social Work in Health Care 39(1-2):29-47.

Kumar, R., P. Jha, P. Arora et al. 2006. "Trends in HIV-1 in young adults in south India from 2000 to 2004: A prevalence study," Lancet 367(9517): 1164-1172.

Majumdar, B. 2004. "An exploration of socioeconomic, spiritual, and family support among HIV-positive women in India," Journal of the Association of Nurses in AIDS Care 15(3): 37-46.

Mehta, S.H., A. Gupta, S. Sahay et al. 2006. "High HIV prevalence among a high-risk subgroup of women attending sexually transmitted infection clinics in Pune, India," Journal of Acquired Immune Deficiency Syndrome 41(1): 75-80.

National AIDS Control Organisation (NACO). 2007. "NACP III: Programme priorities and thrust areas," available at $<$ http://www.nacoonline.org/ National_AIDS_Control_Program/Programme_Priorities_and_Thrust_Areas $>$ accessed on 3 August 2008.

National Institute of Health and Family Welfare (NIHFW) and National AIDS Control Organisation (NACO). 2007. Annual HIV Sentinel Surveillance Country Report, 2006. New Delhi: NIHFW and NACO.

Newmann, S., P. Sarin, N. Kumarasamy et al. 2000. "Marriage, monogamy and HIV: A profile of HIV-infected women in south India," International Journal of STD and HIV/AIDS 11(4):250-253.

Registrar General of India (RGI). 2001. Primary Census Abstract, Total Population: Table $A-5$, Series 1. New Delhi: RGI.

Tamil Nadu State AIDS Control Society (TNSACS). 2005. The Tamil Nadu HIV Sentinel Surveillance Report, 2005. Chennai, India.

Thomas, B.E., F. Rehman, D. Suryanarayanan et al. 2005. "How stigmatizing is stigma in the life of people living with HIV: A study on HIV positive individuals from Chennai, South India," AIDS Care 17(7): 795-801. 
